\title{
Mechanical Behavior of Fullerene Reinforced Fiber Composites with Interface Defects through Homogenization Approach and Finite Element Method
}

\author{
P. Prasanthi ${ }^{1}$, G. Sambasiva Rao ${ }^{2}$ and B. Umamaheswar Gowd ${ }^{3}$ \\ ${ }^{I}$ Department of Mechanical Engineering, P. V. P. Siddhartha Institute of \\ Technology, Vijayawada, India \\ ${ }^{2}$ Principal, Sir C. R. Reddy College of Engineering, Eluru, India \\ ${ }^{3}$ Director of Industrial Relations and Placements, JNT University, Anantapur, \\ India \\ phaniprasanthi.parvathaneni@gmail.com
}

\begin{abstract}
Critical imperfections such as Debond, voids and cracks decrease performance of composite structure. Accurate evaluation of properties of composites with above imperfections prevents the catastrophic failure of designing components. In this study, finite element analysis is performed to determine the effective elastic properties of debonded unidirectional composites with Micro and Macro-mechanics approaches. Intensity of fully debonded fibers on the behavior of total composite material is studied. The applicability of the present work is explored for conventional fiber of boron with homogenized nano fullerene particle mixed polymer matrix. The effect of debonding of boron fiber reinforcement on the effective Young's modulus and Poisson's ratio of the composite is demonstrated. The study revealed that transverse Young's modulus $\left(E_{2}\right)$ is extensively affected than longitudinal Young's modulus due to debond.
\end{abstract}

Keywords: Debonding, Buckminster Fullerene, Micromechanics, Macro mechanics, Homogenization

\section{Introduction}

Nanocomposites have been extensively used in various engineering fields for the past decades. Compared with conventional materials, fiber reinforced nanocomposites or particle reinforced nano composites exhibits low density, high strength to weight ratio and high stiffness to weight ratio, high toughness with improved creep resistance and wear resistance. Combining high stiffened nanoparticles to the low modulus polymer matrix, improves the load carrying capacity.

Further reinforcing regular fibers in nano particles mixed polymer instead of pure polymer matrix better enhancement in the mechanical properties are achieved. The interface between the constituents significantly affects the mechanical properties of nano based composites. Prediction of effective mechanical properties of composites is based on the assumptions of perfect bonding. This assumption is inadequate for characterization of composite with imperfect debonds. To analyze composite material properties with the presence of debonding, one needs to select experimental or theoretical approaches.

The experimental techniques lead to the accurate solution for concerned problem. But these methods are expensive in terms of cost and time. Another way to extract the mechanical properties with debonding is possible with theoretical methods such as Micromechanics and Macro mechanics. The micromechanical approaches select a particular portion of a composite known as Representative volume Element. The selection of RVE depends on the shape of the reinforcement and its distribution in the matrix phase. 
The properties obtained from the RVE in terms represent the properties of a composite lamina. Many assumptions need to frame while treating composite lamina with Micromechanics like composite lamina is a free from voids and fiber distribution in matrix material is uniform manner and perfect bonding between the constituents. These assumptions could be the reason for deviation of theoretical from experimental predictions.

Numerical methods such as finite element method are used to nullify some of the assumptions in Micromechanics approaches. The approximation in finite element method is justified with finite element refinement and proper benchmark validation. A. Sami et al. [1] Evaluated Single walled carbon nanotubes reinforced composites mechanical properties. The methodology opted in determining the properties are the powerful Micromechanics approach.

Using the Micromechanics approach another researcher, H. L. Duan et al., [2] predicted effective modulus of solid particles containing nano in-homogeneities. Interestingly, Micromechanics and finite element method are used in predicting the Mechanical properties of polymer composite materials with clay nanoparticles. Hua Liu et al., [3] Research involved Micromechanics methodology in determining the mechanical performance of nano particles and nano-platelets. In addition work is further extended by comparing their reinforcing efficiencies.

A continuum mechanics approach with the help of finite element method used to estimate the elastic response of CNT based composites by means of a square shaped representative volume element achieved by X.L. Chen et al., [4]. The macroscopic elastic properties of CNT composites are presented by using finite element method by N. HU et al., [5]. G. M. Odegard et al., [6] Developed constitutive models to relate the atomistic simulation of nano-structured material to continuum models of corresponding bulk material of polymer composites reinforced with single walled carbon nanotubes. The effect of the chiral vector of carbon nanotubes (CNTs) and Young's modulus of matrix material influence on the interfacial stress of CNT reinforced composites are evaluated using finite element method by H. Wang et al., [7].

J. S. Snipes et al., [8] Selected Generalized Method of Cells, one of Micromechanics models to determine the effective properties of gold nano-rod reinforced in polymer matrix composites. Developments were made by introducing an analytical model with spherical inclusions by G.K. Hu et al., [9] P. K. Valavala and G. M. Odegard [10] presented different modeling techniques on nano reinforced composites as a review. Micromechanics and finite element method were used by China L et al., [11] observe the failure of the carbon nanotube (CNT) reinforced composites.

Stress transfer in single wall carbon nanotube reinforced polymer composites is predicted by A. Haque et al., [12]. U. A Joshi et al., [13] used a hexagonal representative volume element (RVE) under lateral loading conditions. Different properties of the metal matrix composite are predicted using ANSYS software by G. G. Sozhamannan et al., [14] whose reinforcement is in particle form. F.V. Antunes et al., [15] focused on fatigue life of composite using FEM. J. Lorca et al., [16] worked on composite material plus Elastoplastic matrix when the loading is tension and made conclusions using finite element analysis. V. K. Srivastava et al., [17] investigated the impact of shape and size of reinforcement on the mechanical properties of composite material using Micromechanics using finite element method. Importance of finite element method in handling Micromechanics analysis of nano composites is realized from the past literature.

The objective of the present analysis is to use a three dimensional finite element method to address various issues pertaining to interface defects at nano-level and their influence on global response of conventional composites properties. The present investigation is carried out in following cases is as follows: 
Case-(i): Investigation of mechanical properties of composite with

Nano fullerenes perfectly bonded with polymer matrix.

Case-(ii): The influence of debonding of boron fiber with homogenized fullerene

Mixed matrix

\section{Problem Modeling:}

2.1. Geometric Modeling: Figures 1 and 2 represent the distribution of reinforcement in matrix phase. The case (i) studies the mechanical properties of fullerene reinforced in a pure polymer matrix, case (ii) Boron fiber, uniform distribution in the homogenized fullerene mixed matrix. In case (i), due to symmetric response of reinforcement for the mechanical loading, one eighth model is considered for the prediction of mechanical properties.

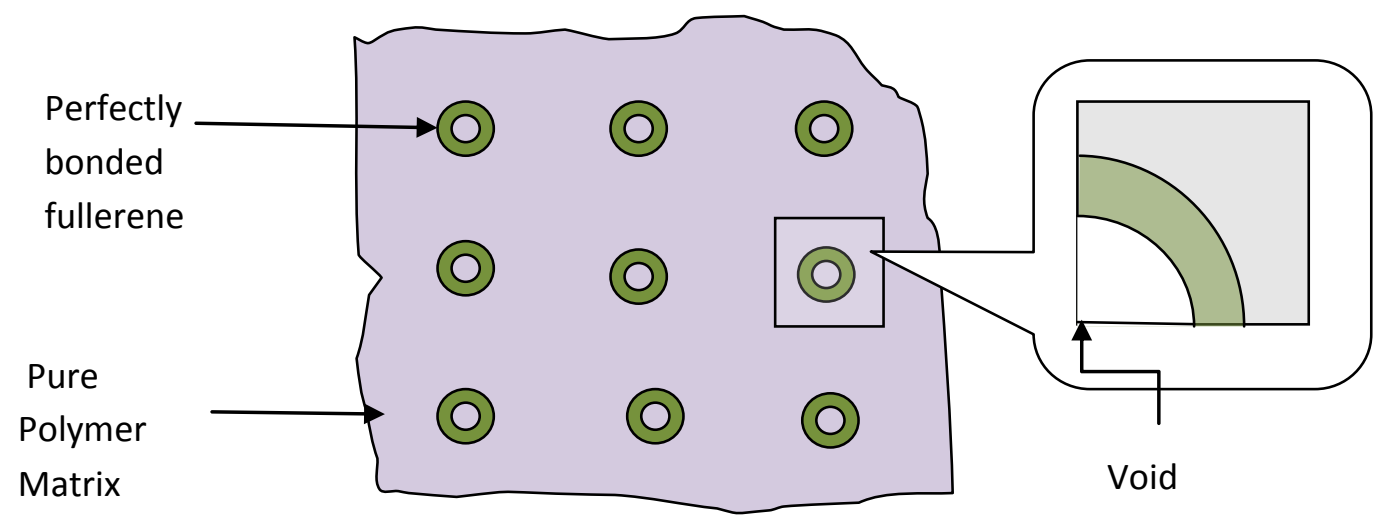

\section{Figure 1. Uniform Distribution of Buckminster Fullerenes in Polymer Matrix Phase of Case (i)}

The dimensions taken for the micromechanical analysis are calculated based on the volume fraction of the nano reinforcement by maintaining uniform thickness of the Fullerene i.e., $0.4 \mathrm{~nm}$. The outer radius of the fullerene $\mathrm{r}_{\mathrm{o}}=5 \mathrm{~nm}$ and inner radius of the fullerene ri=4.6nm [21]. In case (ii), the Boron fibers are reinforced in Homogenized fullerene mixed polymer matrix. Instead of maintaining perfect bonding between all boron fibers with homogenized fullerene mixed matrix, few fibers are treated with imperfect debonding as shown in Figure 2. Dimensions considered for the side of the square unit cell are $a=100$ units and radius of the boron fiber are calculated based on the volume fraction of the fiber which is varied from 0.1 to 0.75 . Due to non symmetrical response of the fiber with different interface conditions, one symmetric model is not sufficient to reveal the total composite material behavior. Thus, one eighth model with fiber fully debonded matrix composite properties and fiber with perfectly bonded composite properties are extracted individually. Afterward, the extracted properties are used in the Macro mechanics approach to quantify the debonded fiber influence in the total composite material.

In Macro-mechanics method in case ii, nine blocks are modelled in a square pattern. Some blocks represent fibers fully debonded and the remaining blocks represents the perfectly bonded fibers. The junctions of blocks are merged in all aspects for smooth transfer of mechanical load. The problem is tackled with finite element based software ANSYS. 


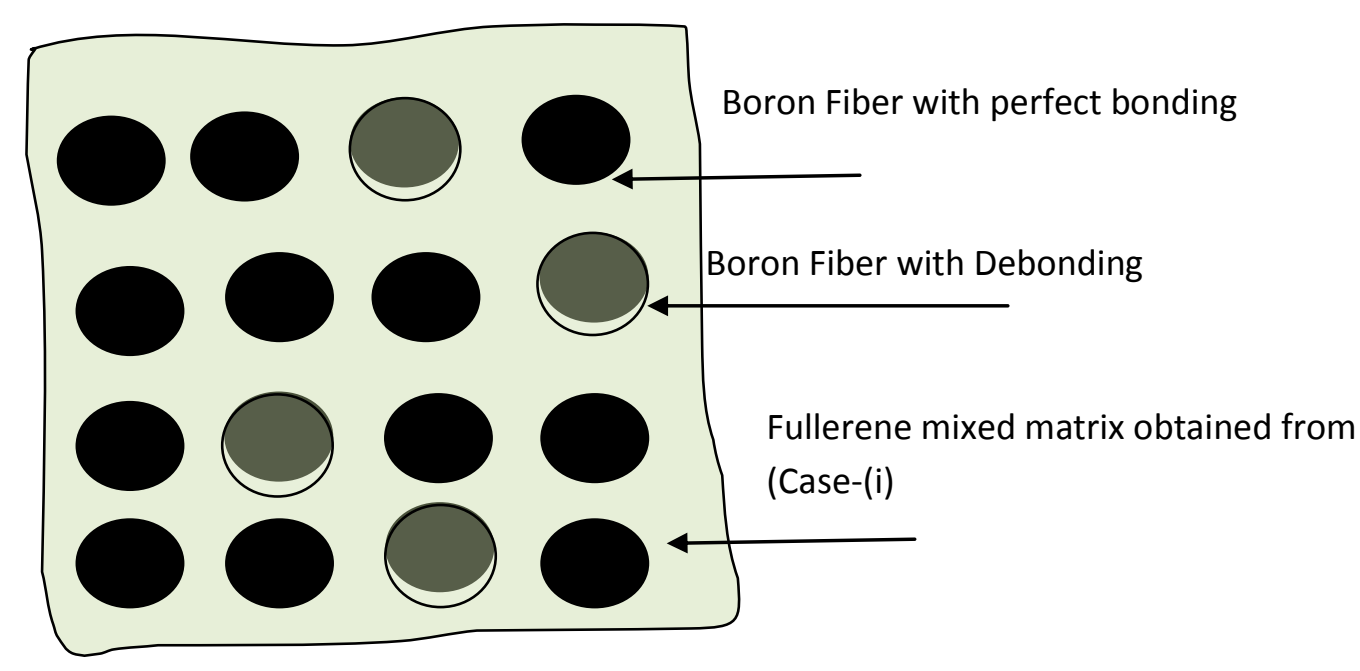

Figure 2. Square Unit Cell of a Composite with Layers of Fibres having Fully Debonded with Matrix

\subsection{Boundary Conditions}

The boundary conditions are applied in such a way that the finite element model should act as a part of the total array of composite materials. Due to symmetry in loading, geometry and boundary conditions one eighth of the unit cell is modeled in the analysis. A uniform tensile load of $1 \mathrm{MPa}$ is applied to the $\mathrm{Z}$-face to obtain a uni-axial state of stress that facilitates usage of simple hook's law for predicting Young's modulus of resulting composite for case (i). In case (ii) transverse properties are obtained by applying same load in the positive $\mathrm{X}$-direction.

\subsection{Material Properties}

Since exact properties for a continuum model of buckminster fullerene are not evident from the available literature analysis is performed by considering the properties of the continuum model of CNT given by Tserpes (2005). The assumption is fairly justified as the present investigation is to assess response of nano particle embedded in the matrix phase with certain extent of perfect bonding but not to assess the exact properties. Various properties used in present investigation: (i) Buckminster Fullerene: Young's modulus $E_{P}$ $=1000 \mathrm{GPa}$, Poisson's ratio $\left(v_{\mathrm{p}}\right)=0.3$. Polymer Matrix: Young's $\mathrm{E}_{\mathrm{m}}=5.171 \mathrm{GPa}$, Poisson's ratio. $v_{\mathrm{m}}=0.35$ Tserpes (2005) [18], (ii) Boron Fiber (isotropic): E=400Gpa, $v$ $=0.2$.

\subsection{Finite Element Modeling}

The present problem modelled with finite element software ANSYS. Solid 95 elements are opting for the discretization of the constituents. Each element of solid 95 characterized by 20 nodes and each node shows six degrees of freedom in the translation and rotation directions. The interface between reinforcement and matrix is provided by CONTA174 and TARGE170 ELEMENTS. The refined and converged finite element models are used to report the observation of the present work. 


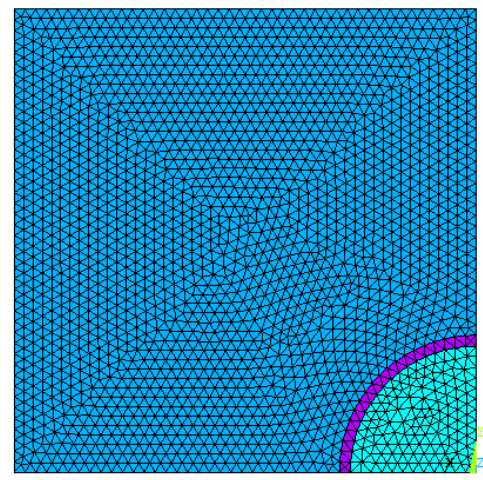

\section{Figure 3. FE Model of Fullerene Reinforced Composites with Perfect Bond between Constituents}

\subsection{Verification of FE Results with References}

Example 1. Hong Teng et al., [20] applied 3D finite element method and calculated the average Young's modulus of particulate reinforced composites and validated his results with exact analytical theories. In order to conform to the proper modeling of the composite, a problem similar to one of the cases solved and verified with his results [Figure 4]. A very close agreement between the results can be observed.

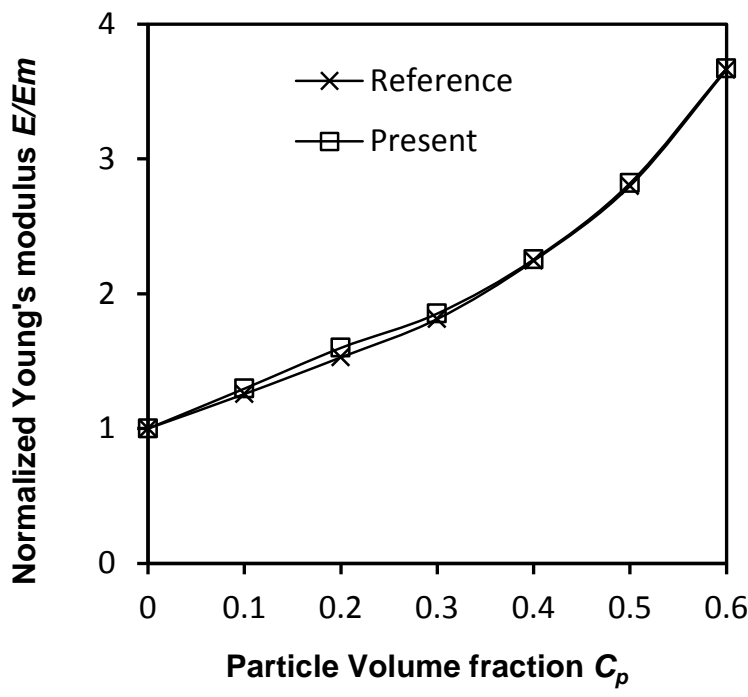

Figure 4. Young's Modulus $E / E_{m}$ versus the Particle Volume Fraction $c_{p}$

\subsection{Model with other Analytical Model}

Mesh convergence is carried out for solid particulate reinforced composite by increasing the number of the element on the side of the cube of finite element model. The converged solutions are compared with the analytical models. Hence the mesh density is found adequate for sufficient solution accuracy. The finite element model is compared with various analytical models suggested by Halpin Tsai, Einstein and Guth and Mooney. The normalized Young's modulus is obtained from finite element method for different volume fraction of the reinforcement and these values are compared with analytical values obtained from above mentioned analytical models. The results are close at lower volume fraction of the reinforcement and the deviations of analytical results with the results, increasing with increasing the volume fraction of particles [Figure 4]. The deviation of the analytical results may be due to the assumptions made in the derivation of respective equations. Shao-Yun Fu et al., [21] mentioned many empirical or semi-empirical 
equations to predict the modulus of particulate polymer composites. The finite element results obtained from the present work compared with several analytical expressions [21].

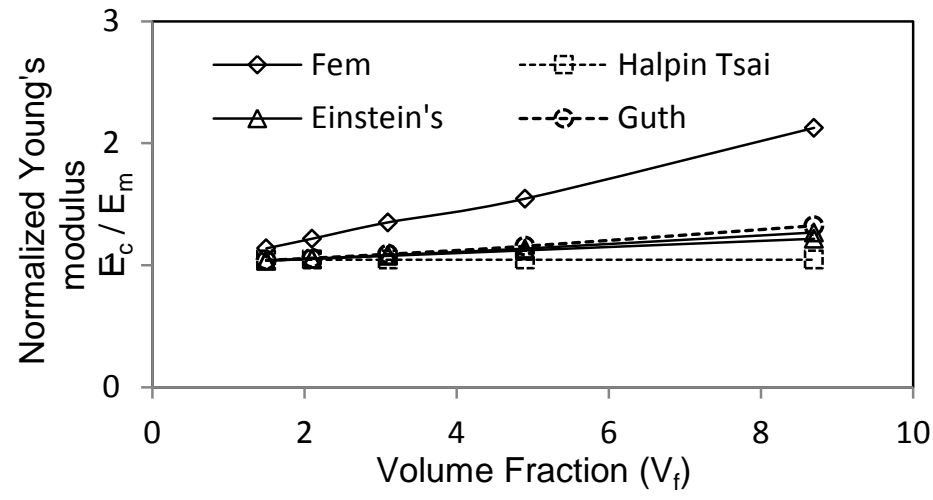

Figure 5. Variation of Normalized Young's Modulus with Volume Fraction

\subsection{Mesh Convergence for Buck Minster Fullerene Composite}

Further mesh convergence is carried out for hollow spherical shaped particle reinforced composite and the results are presented in Table 1.

Table 1. Mesh Convergence Table for Hollow Particle at $2 \%$ Volume Fraction

\begin{tabular}{|c|c|c|}
\hline No of elements on side of the cube & $\begin{array}{l}\text { Normalized Young's } \\
\text { modulus }\left(\mathrm{E}_{\mathrm{zc}} / \mathrm{E}_{\mathrm{m}}\right)\end{array}$ & $\begin{array}{l}\text { Normalized Poisson's } \\
\text { ratio }\left(v_{\mathrm{zx}} / v_{\mathrm{m}}\right)\end{array}$ \\
\hline 11 & 1.178997 & 0.976153 \\
\hline 13 & 1.17892 & 0.976107 \\
\hline 17 & 1.17892 & 0.976183 \\
\hline 24 & 1.178842 & 0.976137 \\
\hline 26 & 1.178842 & 0.976137 \\
\hline
\end{tabular}

\section{Elastic Properties of Fullerene/epoxy Composites:}

The analytical solution for elastic response in conventional composite is readily available. However, the analytical solution for elastic properties is quite complex for nano composite material such as nano fullerene reinforced composites. Thus, the numerical finite element models have been developed to suit the different cases considered for the present work. The converged finite models are adopted to bring out the solutions for the current study.

Figure 6 Shows the variation in normalized Young's modulus with respect to the volume fraction of buckminster fullerene. The normalized Young's modulus increases with increasing the volume fraction of the fullerene. This is due to increasing the stiffness of the resulting composite. Variation in the normalized Poisson's ratio with respect to the volume fraction of fullerene is shown in Figure 7. The normalized Poisson's ratio slightly decreases with increasing the volume fraction of the fullerene. The reason behind this is a decrement in the lateral and longitudinal strains due to the increment of the stiffness. 


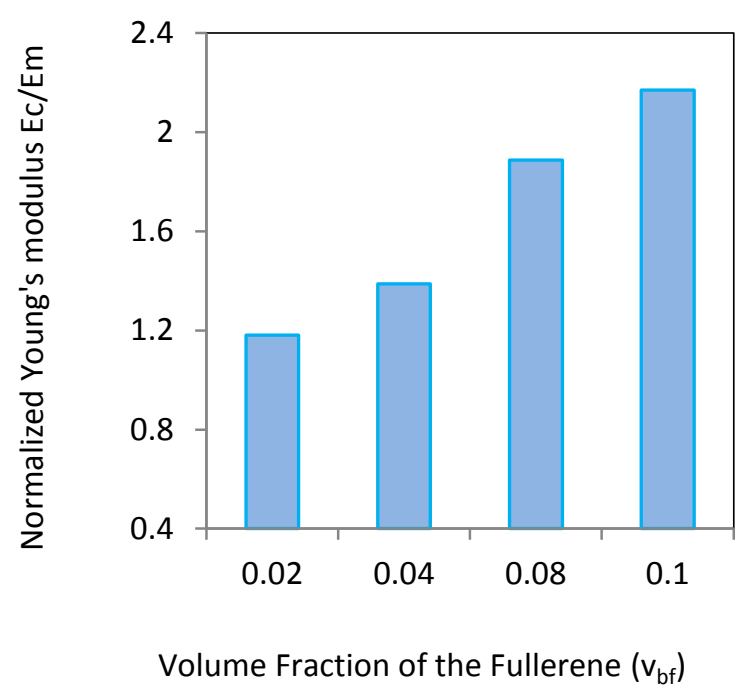

Figure 6. Ec/Em with Volume Fraction of the Fullerene

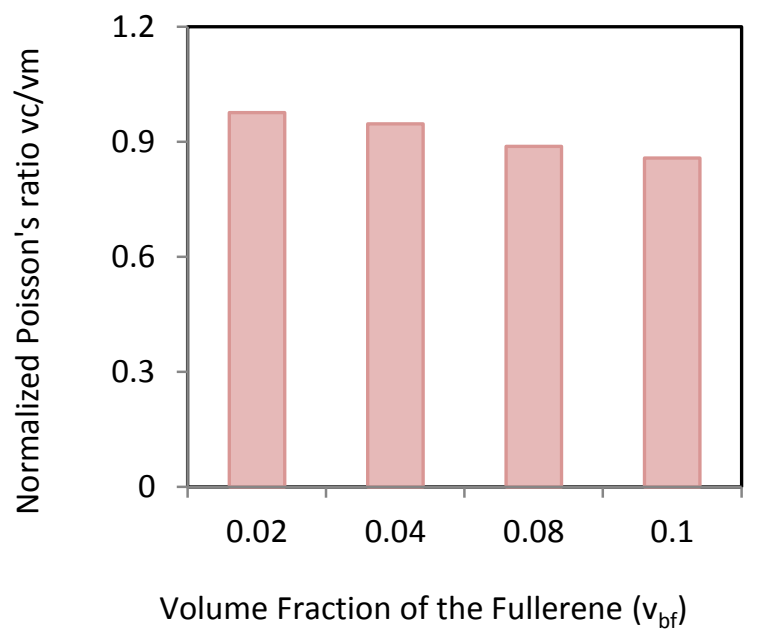

Figure 7. $v_{\mathrm{c}} \boldsymbol{v}_{\mathrm{m}}$ with Volume Fraction of the Fullerene

\section{Interface Defect at Boron Fiber Reinforced in Fullerene Mixed Matrix:}

The importance of the present study is depicted with the Following Figure 8. The Boron fiber is uniformly distributed in the homogenized fullerene mixed matrix obtained from case (i). Instead of treating perfect bonding at all the Boron fiber, one or three fibers are maintaining debonding between the constituents. Total nine fibers are considered for the analysis. Geometrically center fiber is subjected to debonding with the matrix phase and the rest of the all the fibers are perfectly bonded with their constituents. First the problem is solved by using micromechanics at 0.1 volume fraction of boron fiber. (Figure 11) Later same analysis is performed by Macro mechanics approach (Block model). (Figure 12) Well agreement found between the results obtained from the both the analyses. Table 2 . To decrease the computational time, the analysis is performed by Macro mechanics approach. 
Table 2. \% Error between Micro and Macro Analysis

\begin{tabular}{|l|l|l|l|l|l|l|l|l|l|l|l|l|l|l|}
\hline $\mathrm{V}_{\mathrm{f}}$ & $\mathrm{V}_{\mathrm{bf}}$ & \multicolumn{1}{|c|}{$\begin{array}{l}\text { No of } \\
\text { Debond } \\
\text { ed fiber } \\
\text { in total } \\
\text { of 9 }\end{array}$} & $\begin{array}{l}\mathrm{E}_{1} \\
(\mathrm{GPa})\end{array}$ & $\mathrm{V}_{12}$ & $\begin{array}{l}\mathrm{E}_{2} \\
(\mathrm{GPa})\end{array}$ & $\mathrm{V}_{21}$ & $\begin{array}{l}\mathrm{E}_{1} \\
(\mathrm{GPa})\end{array}$ & $\mathrm{V}_{12}$ & $\begin{array}{l}\mathrm{E}_{2} \\
(\mathrm{GPa})\end{array}$ & $\mathrm{V}_{21}$ & $\begin{array}{l}\mathrm{E}_{1} \\
\%\end{array}$ & $\begin{array}{l}\mathrm{V}_{12} \\
\%\end{array}$ & $\begin{array}{l}\mathrm{E}_{2} \\
\%\end{array}$ & $\begin{array}{c}\mathrm{V}_{21} \\
\%\end{array}$ \\
\hline 0.1 & 0.02 & one & 45.4 & 0.32 & 7.56 & 0.05 & 45.5 & 0.3 & 7.6 & 0.05 & 0.2 & 0.1 & 0.9 & 0.4 \\
\hline 0.1 & 0.02 & Three & 45.3 & 0.33 & 7.04 & 0.05 & 45.5 & 0.32 & 7.10 & 0.05 & 0.3 & 1.0 & 0.9 & 0.4 \\
\hline
\end{tabular}

One eighth model with boron fiber fully debonded with homogenized fullerene mixed matrix composite properties and same fiber with perfectly bonded composite properties are extracted individually. (Figure 9 and 10). Later, the extracted properties are used in the Macro mechanics approach to quantify the debonded boron fiber influence in the total composite material by assigning debonded fullerene properties to one or three of the total nine blocks and the remaining block are assigned with defect free fullerene composites. For the analysis of one debonded fiber in total nine fibers reinforced matrix, middle block is attributed with debonded fiber matrix properties (Figure 12) and all the remaining blocks are attributed with debond free fiber reinforced composite resultant properties.

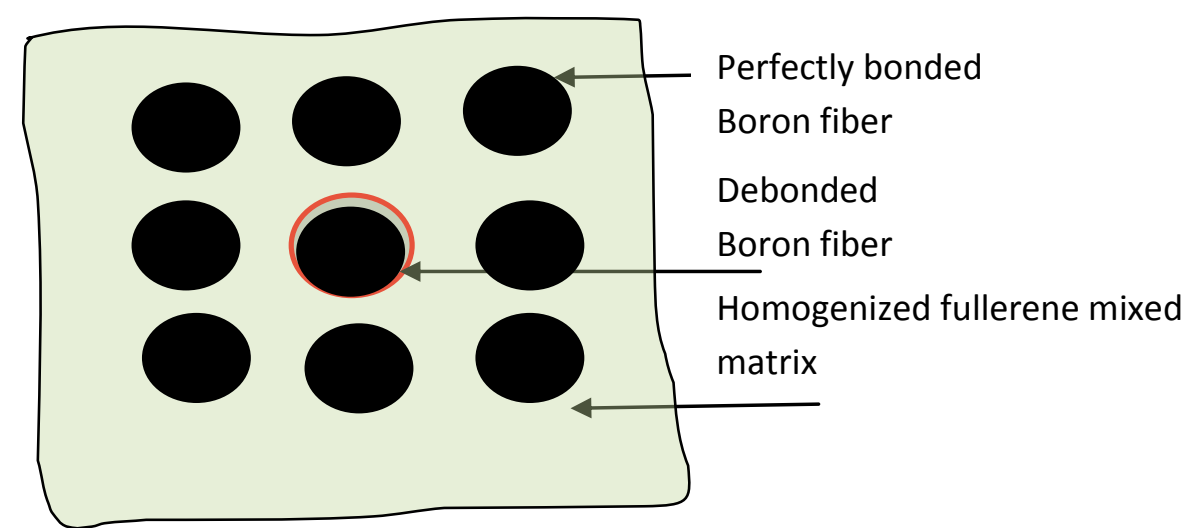

Figure 8. Uniform Distribution of Boron Fibers with Interface Defects in Homozinized Perfectly Bonded Fullerene Mixed Matrix
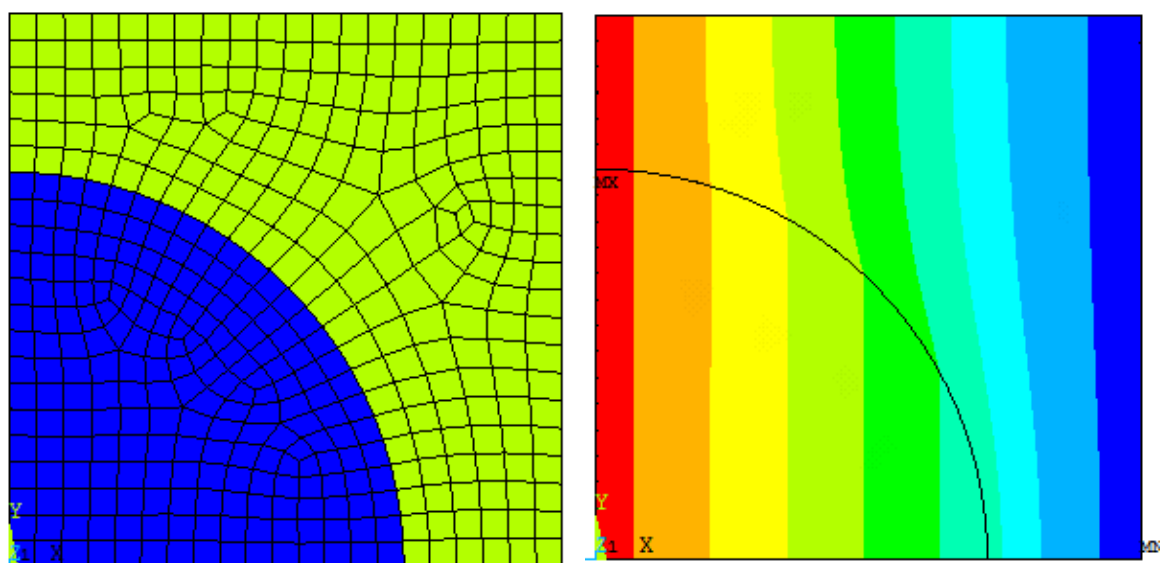

Figure 9. FE Model of Fiber Reinforced Composites with Perfect Bond between the Constituents 

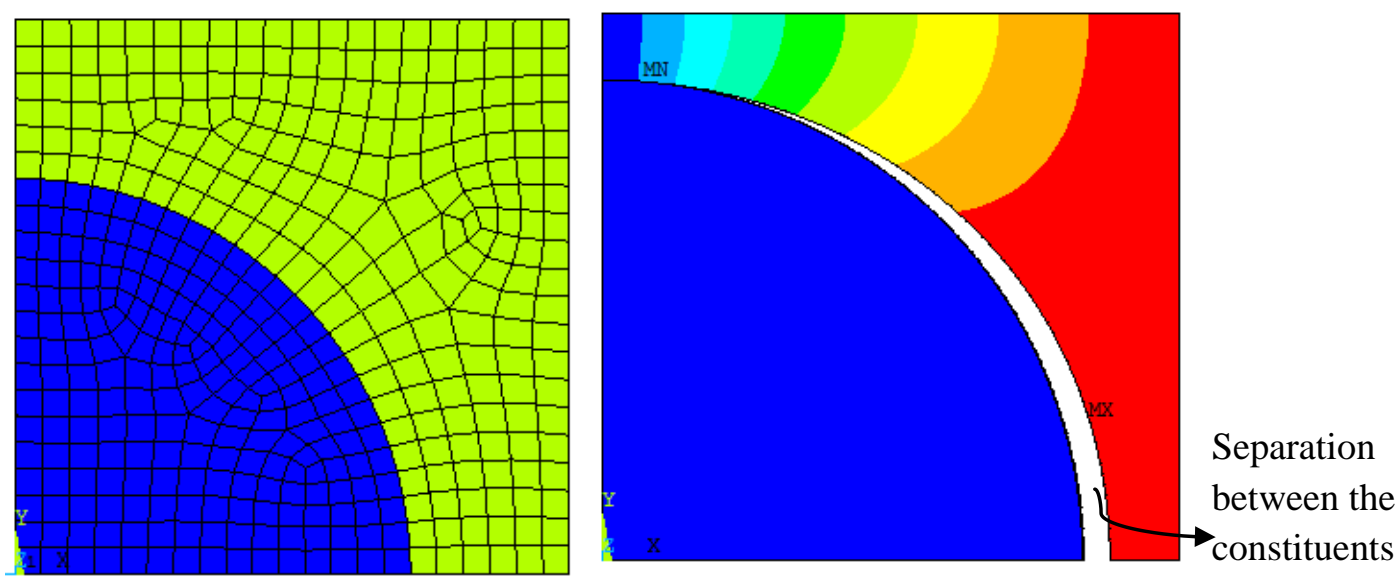

\section{Figure 10. FE Model of Fiber Reinforced Composites with Debond between the Constituents}

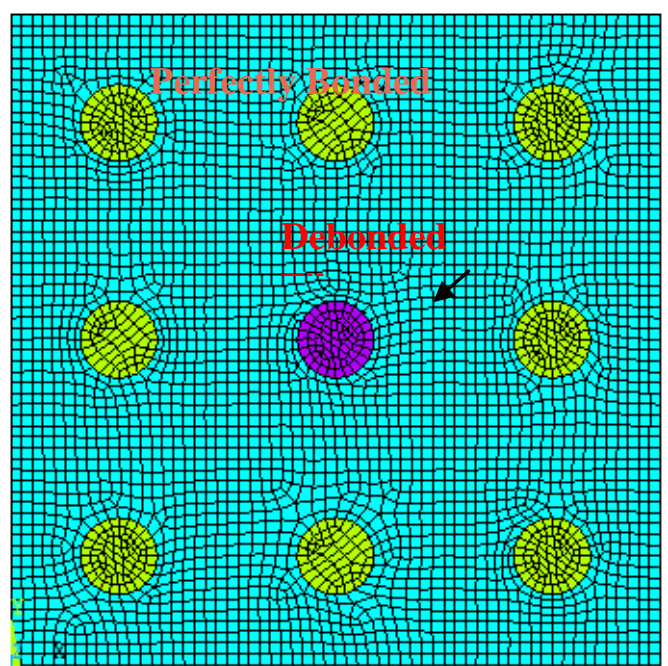

Figure 11. FE Model (Micro Mechanics) with 1 out of 9 Defects

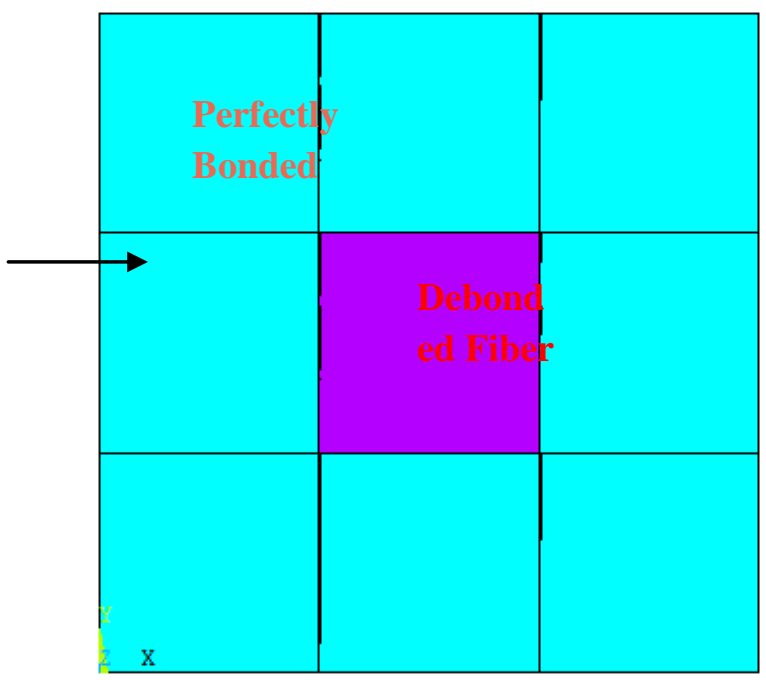

Figure 12. FE model (Macro Mechanics) with 1 out of 9 Defects

In this section the effect of debond of boron fiber with homogenized fullerene mixed polymer matrix at $10 \%$ of volume fraction of fullerene is presented. The Young's moduli, Poisson's ratio of the composite in both longitudinal and transverse direction are evaluated using Finite element based Software ANSYS. For a clear understanding of the debonding influence on the resulting properties, all the properties are compared with defect free (perfect bonding) composite properties.

Longitudinal modulus $\left(\mathrm{E}_{1}\right)$ increases with increase in volume fraction of boron fiber, however, no changes are noticed in composite with perfect bonded boron fiber or one debonded boron fiber with homogenized fullerene mixed matrix in a total of 9 fibers. (Figure 13). This is due the reason that dominated stiffness of fiber compared with the matrix material shows tremendous strength in fiber aligned direction (longitudinal) even it affected by debond. 
Well agreement is observed between longitudinal Young's modulus $\left(\mathrm{E}_{1}\right)$ with the rule of mixtures and Transverse modulus $\left(\mathrm{E}_{2}\right)$ with the inverse rule of mixtures at $10 \%$ of fullerene in polymer matrix without any debonding between the constituents Table 3 .

The associated Poisson's ration $\left(v_{12}\right)$ of composite material decreases with a rise in the volume fraction of the Boron fiber. The trend is same for both debonding and perfect bonded composites. A minor decrement in the property is noticed at lower volume fraction of the boron fiber with debonding compared with perfect bonded composite properties and the decrement is diminished with increasing the boron fiber volume fraction (Figure 14).

The transverse modulus $\left(\mathrm{E}_{2}\right)$, starting with its growth from lower volume fraction, jumped to peak value at a higher volume fraction of the reinforcement. The effect of debond is clearly observed on Transverse modulus $\left(\mathrm{E}_{2}\right)$. Considerable variation in the property with the debonding compared with perfectly bonded composite property is noticed. The variation is high at fiber dominated volume fraction and the deviation is low at lower volume fraction of the Boron fiber. This is due to the reason that increment in the effective debonded area with increasing the fiber volume fraction. (Figure 15)

Transverse Poissons ratio $v_{21}$ (Figure 16) showed different responses due to debond of the boron fiber with homogenized fullerene mixed matrix. At lower and higher volume fractions of boron fiber, the maximum difference in the property due to debonding is obtained because at lower volume fraction of fiber the role of matrix plays dominated role which promotes more strain in the longitudinal direction as a result the transverse modulus decrement is high and the same effect of longitudinal strain is obtained due to dominated debonded area at a higher volume fraction of the fiber.

The Figures 17-20 show the behavior of Boron composite material with high intensity in the defects, i.e., three boron fibers out of nine are debonded with homogenized fullerene mixed matrix (3 out of 9). All extracted properties of longitudinal Young's modulus $\left(\mathrm{E}_{1}\right)$, longitudinal Poisson's ratio $\left(\mathrm{v}_{12}\right)$ and Transverse Poisson's ratio $\left(v_{21}\right)$ yielded same trend as that of 1 out of 9 defected composite, with slight diminishing magnitude due to high concentration of debonded fibers in the composite ( 3 out of 9). The transverse modulus $\left(\mathrm{E}_{2}\right)$ is greatly affected due to high concentration of debonded fibers in the matrix. It is about $34 \%$ at higher volume fraction of Boron fiber (75\%).

Table 3. \% Error between FE Results with Analytical Expressions of Boron Fiber Reinforced in Homogenized Fullerene Mixed Matrix without any Defect $\left(V_{b f}=10 \%\right)$

\begin{tabular}{|r|l|l|r|r|r|r|}
\hline $\mathrm{V}_{\mathrm{f}}$ & $\mathrm{E}_{1}$ & $\mathrm{E}_{1}$ Rom & \multicolumn{1}{l|}{ \% error } & $\mathrm{E}_{1} / v_{12}$ & $\mathrm{E}_{2} / v_{21}$ & $\mathrm{E}_{1} / v_{12}-\mathrm{E}_{2} / v_{21}$ \\
\hline 10 & 50.11275 & 50.10376 & 0.01795 & 174.83953 & 174.7793 & 0.060189 \\
\hline 20 & 88.99964 & 88.98112 & 0.020818 & 324.57601 & 324.3804 & 0.19558 \\
\hline 30 & 127.8756 & 127.8585 & 0.013392 & 486.90238 & 486.547 & 0.355407 \\
\hline 40 & 166.8224 & 166.7358 & 0.051895 & 662.7261 & 662.164 & 0.562153 \\
\hline 50 & 205.6471 & 205.6132 & 0.016472 & 851.6867 & 851.4986 & 0.188064 \\
\hline 60 & 244.5107 & 244.4906 & 0.008251 & 1059.4362 & 1059.111 & 0.324756 \\
\hline 70 & 283.3744 & 283.3679 & 0.002295 & 1292.5481 & 1289.524 & 3.02415 \\
\hline 75 & 302.8367 & 302.8066 & 0.009954 & 1426.9922 & 1426.919 & 0.073469 \\
\hline
\end{tabular}




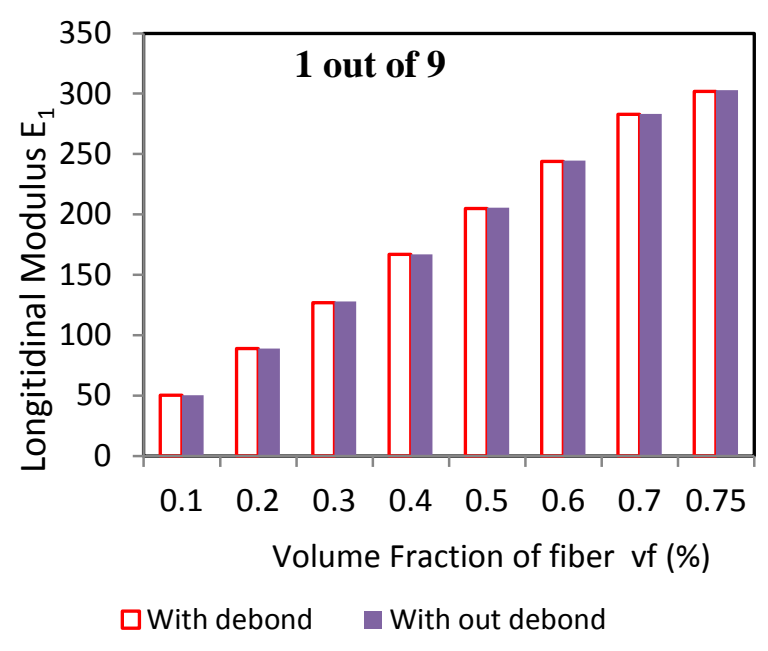

Figure 13. $E_{1}$ of Boron Fiber with Homogenized Fullerene Mixed Matrix with Debond

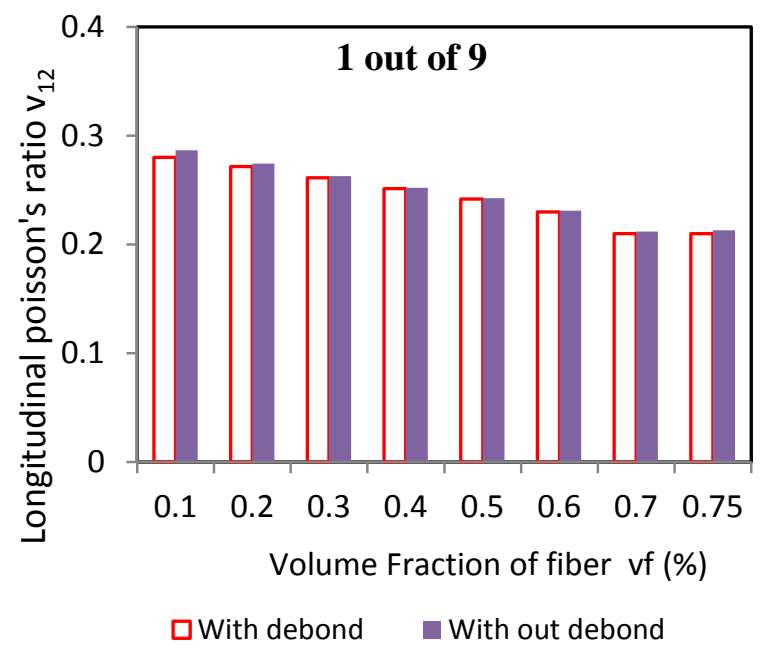

Figure 14. $v_{12}$ of Boron Fiber with Homogenized Fullerene Mixed Matrix with Debond

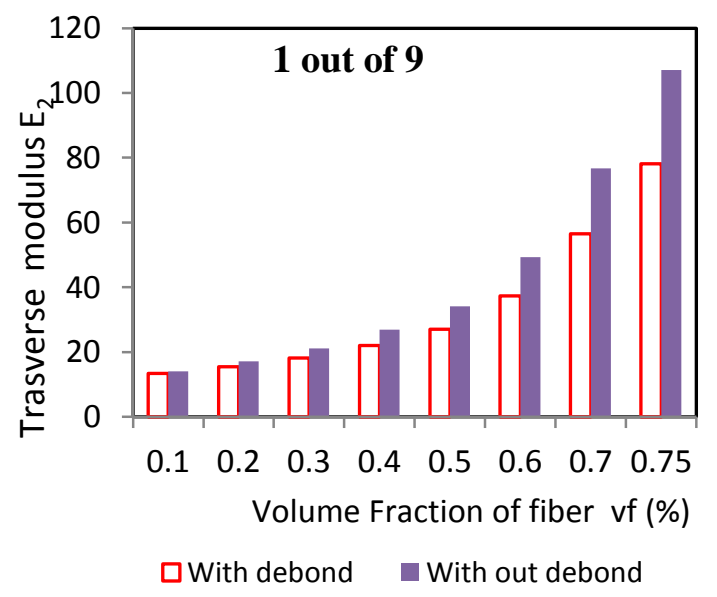

Figure 15. $E_{2}$ of Boron Fiber with Homogenized Fullerene Mixed Matrix with Debond 


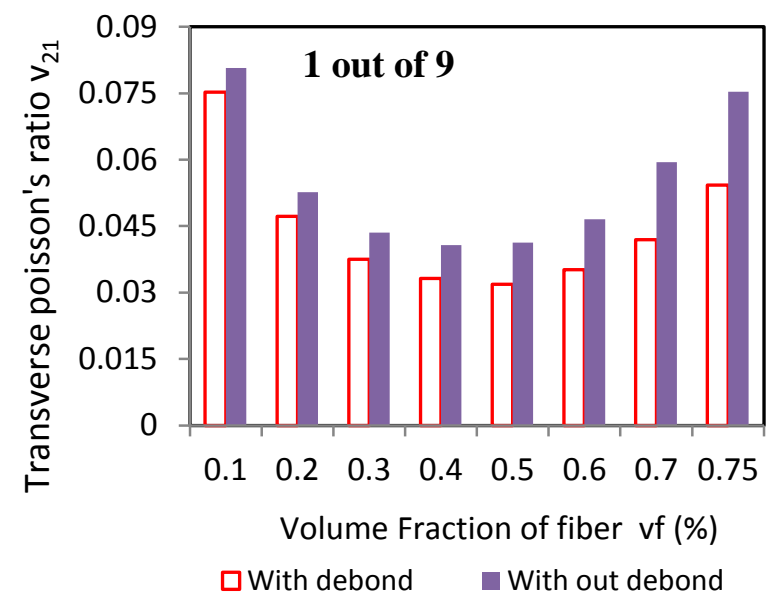

Figure 16. $v_{21}$ of Boron Fiber with Homogenized Fullerene Mixed Matrix with Debond

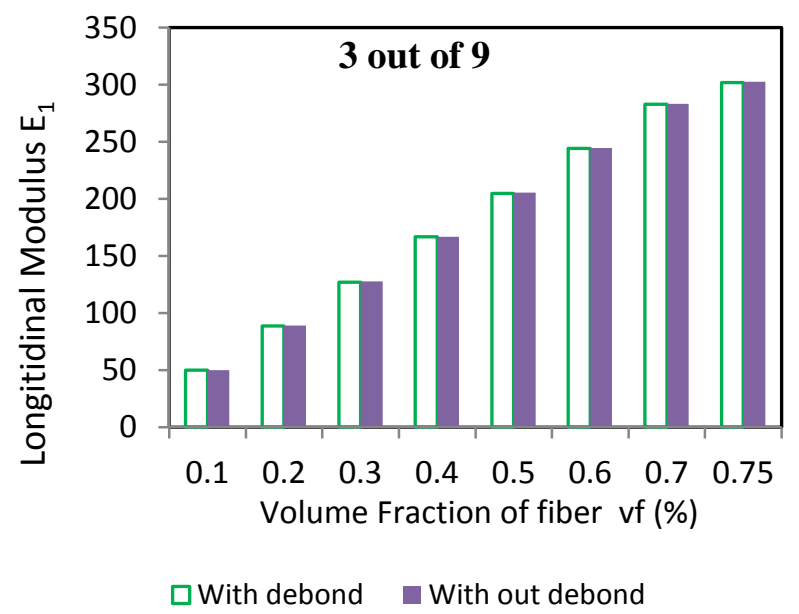

Figure 17. $E_{1}$ of Boron Fiber with Homogenized Fullerene Mixed Matrix with Debond

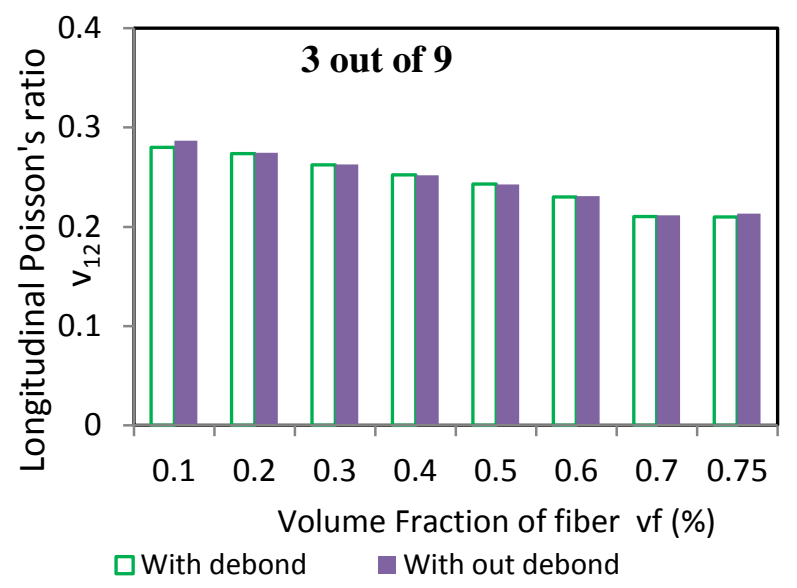

Figure 18. $v_{12}$ of Boron Fiber with Homogenized Fullerene Mixed Matrix with Debond 


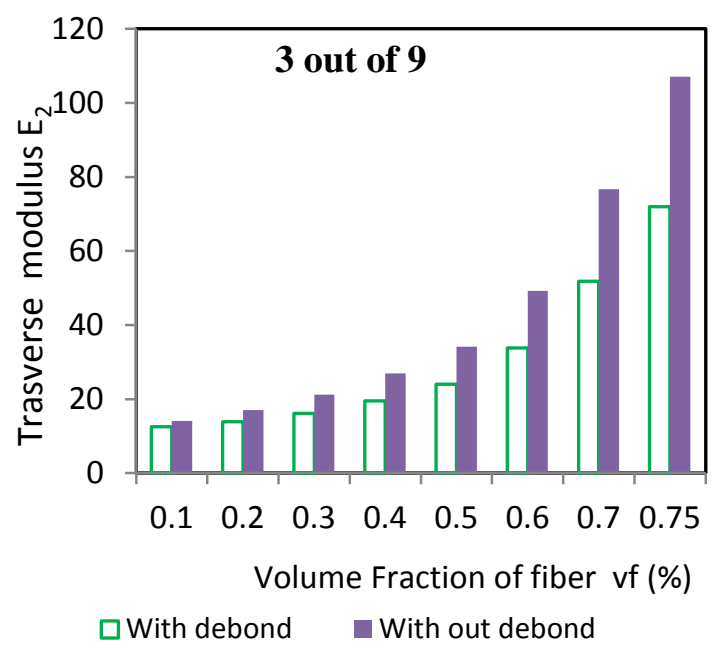

Figure 19. $E_{2}$ of Boron Fiber with Homogenized Fullerene Mixed Matrix with Debond

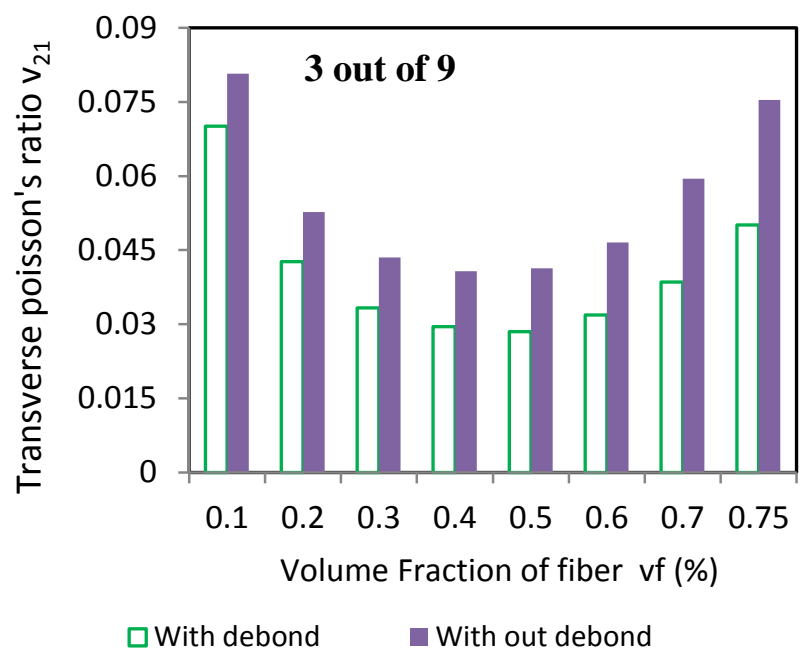

Figure 20. $v_{21}$ of Boron Fiber with Homogenized Fullerene Mixed Matrix with Debond

\section{Conclusions}

The overall mechanical behaviors of composite with different levels of defects are investigated using three dimensional finite element methods with correlations of Micromechanics and Macro mechanics methodology. On the basis of a three dimensional finite element analysis with homogenization method, the following conclusions are acquired

- Imperfect bonding of Boron fiber with homogenized fullerene mixed polymer matrix diminished the resulting composite material Young's modulus and Poisson's ratio in a significant manner.

- The longitudinal modulus $\left(\mathrm{E}_{1}\right)$ of boron fiber reinforced in homogenized perfect fullerenes mixed matrix is not degraded as that of transverse modulus $\left(\mathrm{E}_{2}\right)$ due to debond 
- The influence of interface debonding between the constituents is insignificant on longitudinal Poisson's ratio $\left(v_{12}\right)$ than transverse directions $\left(v_{21}\right)$.

\section{NOMENCLATURE}

- $r_{0}=$ Outer radius of the buckminster fullerene

- $\mathrm{r}_{\mathrm{i}}=$ Inner radius of the buckminster fullerene

- $\mathrm{E}_{\mathrm{bf}}=$ Young's modulus of the buckminster fullerene

- $\mathrm{E}_{\mathrm{m}}=$ Young's modulus of the matrix

- $\mathrm{E}_{\mathrm{c}} / \mathrm{E}_{\mathrm{m}}$, Normalized Young's modulus of fullerene composites

- $v_{\mathrm{c} /} v_{\mathrm{m}},=$ Normalized Poisson's ratio of the composite

- $\mathrm{V}_{\mathrm{f}}=$ volume fraction of the fiber reinforcement

- $\mathrm{V}_{\mathrm{bf}}=$ volume fraction of the buckminster fullerene reinforcement

- $\mathrm{E}_{1}=$ Longitudinal Young's modulus of T300 fiber reinforced composites

- $\mathrm{E}_{2}=$ Transverse Young's modulus of T300 fiber reinforced composites

- $\mathrm{V}_{12}, \mathrm{~V}_{21}=$ longitudinal and transverse Poisson's ratio of T300 fiber reinforced composites

\section{References}

[1] A. Selmi, C. Friebel, I. Doghri and H. Hassis, "Prediction of the Elastic Properties of Single walled Carbon Nanotube Reinforced Polymers: A Comparative Study of Several Micromechanical Models", Composites Science and Technology, vol. 67, (2007), pp. 2071-2084.

[2] H. L. Duan, J. Wang, Z. P. Huang and B. L. Karihaloo, "Size-dependent Effective Elastic Constants of Solids Containing Nano-inhomogeneities with Interface Stress", Journal of the Mechanics and Physics of Solids, vol. 53, (2005), pp. 1574-1596.

[3] H. Liu and L. Catherine Brinson, "Reinforcing Efficiency of Nanoparticles: A simple Comparison for Polymer Nanocomposites", Composites Science and Technology, vol. 68, (2008), pp. 1502-1512.

[4] X. L. Chen and Y. J. Liu, "Square Representative Volume Elements for Evaluating the Effective Material Properties of Carbon Nanotube-based Composites", Computational Materials Science, vol. 29, (2004), pp. 1-11.

[5] N. Hu, H. Fukunaga, C. Lu, M. Kameyama and B. Yan, "Prediction of elastic properties of carbon nanotube reinforced composites", Proceedings Royal science, (2005).

[6] G. M. Odegard, T. S. Gates, K. E. Wise and C. Pa E. J. Siochirk, "Constitutive Modeling of Nanotubereinforced Polymer Composites", NASA/CR-2002-211760.

[7] H. Wang, F. Meng and X. Wang, "Transfer Characteristics of Interfacial Stresses Between Carbon Nanotubes and Matrix", Journal of Reinforced Plastics and composites, (2009).

[8] J. S. Snipes, C. T. Robinson and S.C. Baxter, Effects of scale and interface on the three dimensional micromechanics of polymer nanocomposites, Journal of Composite Materials, (2011).

[9] G. K. Hu, G. Guo and D. Baptiste, "A micromechanical model of influence of particle fracture and particle cluster on mechanical properties of metal matrix composites", Computational Materials Science, vol. 9, (1998), pp. 420-430.

[10] P. K. Valavala and G. M. Odegard, "Modeling Techniques for Determination of Mechanical Properties of Polymer Nanocomposites", 34 P.K. Valavala and G.M. Odegard, Rev.Adv.Mater.Sci, vol. 9, (2005), pp. 34-44.

[11] C. Li and T.-W. Chou, "Failure of carbon nanotube/polymer composites and the effect of nanotube waviness", Journal of Composites: Part A, (2009), pp. 1580-1586.

[12] A. Haque and A. Ramasetty, "Theoretical study of stress transfer in carbon nanotubes reinforced polymer matrix composites”, Composite Structures, vol. 71, (2005), pp. 68-77. 
[13] U. A. Joshi, S C Sharma and S P Harsha, "Modelling and analysis of mechanical behaviour of carbon nanotube reinforced composites", Proceedings of the Institution of Mechanical Engineers, Part N: Journal of Nanoengineering and Nanosystems, (2011).

[14] G. G. Sozhamannan, S. Balasivanandha Prabu, R. Paskaramoorthy, "Failures analysis of particle reinforced metal matrix composites by microstructure based models", Materials and Design, vol. 31, (2010), pp. 3785-3790.

[15] F. V. Antunes, J. M. Ferreira, J. D. Costa and C. Capela, "Fatigue life predictions in polymer particle composites", International Journal of Fatigue, vol. 24, (2002), pp. 1095-1105.

[16] J. LLorca and J. Segurada, "Three-Dimensional Multi-particle cell Simulations of Deformation and Damage in Sphere-Reinforced Composites", Materials Science and Engineering, A365, (2004), pp. 267274.

[17] V. K. Srivastava, U. Gabbert, H. Berger and S. Singh, "Analysis of particles loaded fiber composites for the evaluation of effective material properties with the variation of shape and size", International Journal of Engineering, Science And Technology, vol. 3, no. 1, (2011), pp. 52-68.

[18] T. Papanikos, "Finite element modeling of single-walled carbon nanotubes", Composites: Part B, vol. 36, (2005), pp. 468-477.

[19] ANSYS Reference Manuals, (2011).

[20] H. Teng, "Stiffness properties of particulate composites containing debonded particles", International Journal of Solids and Structures, vol. 47, (2010), pp. 2191-2200.

[21] S.-Y. Fu, X.-Q. Feng, B. Lauke and Y.-W. Mai, "Effects of particle size, particle/matrix interface adhesion and particle loading on mechanical roperties of particulate-polymer composites", Composites: Part B, vol. 39, (2008), pp. 933-961.

[22] Y. J. Liu and X. L. Chen, "Evaluations of the effective material properties of carbon nanotube-based composites using a nanoscale representative volume element", Mechanics of Materials, vol. 35, (2003), pp. 69-81. 
International Journal of Advanced Science and Technology Vol.78 (2015) 